\title{
Human Resource Management in Health Care: A Case of Turnover in Long term care
}

\author{
Ron Fuqua, Ph.D., MBA \\ Associate Professor \\ Department of Health Care Management \\ College of Health, Clayton State University \\ 2000 Clayton State Blvd \\ Latrina Walden, RN, MHA \\ Lecturer \\ Department of Health Care Management \\ College of Health, Clayton State University \\ 2000 Clayton State Blvd \\ Kendolyn Smith, PharmD, MS \\ Assistant Professor \\ Department of Health Care Management \\ College of Health, Clayton State University \\ 2000 Clayton State Blvd
}

\begin{abstract}
The management of human resources in long term health care is challenging. Whether it is home care, skilled nursing care, hospice care, rehabilitation, case management, medical supply, or pharmacy, the work force consists of skilled, licensed professionals. In a case study of a vertically integrated long term care organization operating in several states, the turnover rates for various positions and types of organization were calculated and analyzed. The results point to acuity level, type of long term care provider, and the possibility of low pay as factors for turnover rates from an acceptable level to extremely high and unacceptable levels.
\end{abstract}

Keywords: Turnover, Long term care, Human Resources,

\section{INTRODUCTION}

One of the most perplexing human resource management problems among health care organizations is employee turnover. This is costly and is a problem that impacts the quality of care. In the long term care arena, turnover is an even more exacerbating problem. The proportion of entry level employees to professional health care providers is larger than in other areas of health care. While it might be assumed that replacement costs for entry level health care employees is lower than those for professional level employees, the volume of entry level turnover makes employee turnover expense even larger than for professional health care employees.

In a case study of a vertically integrated long term care organization operating in several states, the turnover rates for various positions and types of organization for a calendar year were calculated and analyzed. The data was collected from a single long term care organization operating in multiple states and employing approximately 10,000 employees. 
The vertically integrated health care companies include home health care, hospice, rehabilitation, skilled nursing, medical supply, pharmacy, and the corporate entity. In this case, the data were collected during a consulting engagement.

In analyzing the employee turnover results, specific attention was applied to the type of long term care organization and the specific position of long term care employees. Many potential causes were considered, but no specific analysis was conducted that would identify the causes of turnover. Instead, the traditional causes for employee turnover were included in the discussion of the results found. The results point to the possibility that acuity level, type of long term care provider, and the level of the position and its accompanying low pay as distinguishing factors for turnover rates from an acceptable level to extremely high and unacceptable levels.

The typical conclusions about the contribution of supervisory style in turnover were not able to be identified with the data that was available. Future case analysis will require data that allows the association of supervisors with the turnover of their employees, and more in-depth information regarding the management style of those supervisors.

\section{REVIEW OF THE LITERATURE}

It is no secret that the high rate of turnover has plagued the healthcare industry over the last decade. Unfortunately, researchers across the country are stating that because of the increasing demand in healthcare due to our aging population, the turnover rate for healthcare workers is going to increase. The aging of the baby boom generation could fuel a 75 percent increase in the number of Americans ages 65 and older requiring nursing home care, to about 2.3 million in 2030 from 1.3 million in 2010 (Manthers, 2016). To match the aging population, the turnover rate for our long term care workers has to decrease. Despite variation in how turnover is calculated, there is ample evidence that turnover rates for clinical care staff in nursing homes range between 55\% and 75\% (Tilden, Thompson, Gajewski, \& Bott, 2012). This number represents all of the clinical staff that is represented in long term care.

Certified nursing assistants (CNAs), the largest segment of the workforce and the group delivering the largest percent of direct care, turn over at the highest rate, often approaching 100\% (Tilden, Thompson, Gajewski, \& Bott, 2012). A study conducted in South Carolina by Fitzpatrick concluded that 12 diverse long term care facilities demonstrated an average turnover rate of 65 percent, with a range between 53 and 82 percent (Fitzpatrick, 2002). These statistics are concerning as they allude to a potential shortage of employees in the LTC sector although it is not clear whether or not health care workers change jobs within the long term care sector or leave it entirely (Black, 2015). The Paraprofessional Health Care Institute (2001) estimates CNA turnover costs the industry $\$ 2.5$ billion per year (Tilden, Thompson, Gajewski, \& Bott, 2012). One study on CNA turnover puts this shortage at 200,000 nationwide, however that was done nearly two decades ago (Fitzpatrick, 2002).

In one case study, the Oakland, California-based Medical Hill Rehabilitation Center conservatively estimated CNA replacement costs in 2006 at \$1,961 per person (Tilden, Thompson, Gajewski, \& Bott, 2012). With an annual CNA turnover rate of $94 \%$, this center estimated its replacement cost for CNAs alone was over $\$ 100,000$ a year (Tilden, Thompson, Gajewski, \& Bott, 2012). Since this small sample study was completed in 2006, we can factor in significant inflation as well as an increase in the nursing population which could frankly take this cost to double or even triple its original amount. Seavey (2004) conducted a meta-analysis of the retention and turnover literature and concluded that a minimum direct cost of turnover per person was $\$ 2,500$ (Tilden, Thompson, Gajewski, \& Bott, 2012). 
Interestingly, much research focused on retention of staff in LTC settings has focused on direct care workers, rather than licensed nursing staff (McGilton, Boscart, Brown, \& Bowers, 2014). The direct care worker is responsible for providing most of the activities of daily living (ADL), while the licensed nurse delivers treatments and supervises care (McGilton, Boscart, Brown, \& Bowers, 2014). The reach of a licensed nurse in the care of all the patients in a facility impacts much more than it appears even though the direct care is typically lacking in comparison with the CAN. Turnover of licensed nursing staff in LTC can negatively affect resident outcomes, organizational productivity, and retention of direct care workers (McGilton, Boscart, Brown, \& Bowers, 2014).

With turnover rates in long term care, evaluating the reasons for turnover could result in a valuable conclusion as we attempt to solve the problem. In a study conducted for the licensed nurse, the incentive to stay at the facility was undermined by institutional and organizational factors preventing nurses from performing their roles as they wished (McGilton, Boscart, Brown, \& Bowers, 2014). Responses from nurses in this study mimicked the findings of Alderson (2008) that heavy workloads impose time constraints on nurses that preclude the formation of meaningful nurse-resident relationships and the completion of thorough nursing assessments, both essential elements of person-centered care (McGilton, Boscart, Brown, \& Bowers, 2014). In other words, licensed nurses were unable to perform their duties without significant bureaucratic factors blocking the creativity that can sometimes be displayed by nursing. In addition, the consistent time crunch that has engulfed nursing has dominated in an industry where nurses are supposed to be allowed time to develop long meaningful relationships with patients. As a result, licensed nurses are unable to foster such bonds with the patients. Insufficient staffing levels have been identified by CNA's and nurses as factors that contribute to turnover within this sector (Black, 2015).

It has also been recognized within the research literature that working in LTC is both physically and psychologically demanding (Black, 2015). The literature indicates that unreasonable expectations and being incapable of providing high quality care have been reasons why CNA's have left LTC homes (Black, 2015). Being unable to provide quality care due to heavy workloads is detrimental for CNA's as it threatens their ability to develop meaningful relationships with residents (Black, 2015). Nurses have similarly expressed the need for sufficient compensation to accurately reflect the demands of their positions (Black, 2015). Reducing staff turnover in nursing homes would benefit both the cost to the U.S. health care system, and, most importantly, the care residents receive in the vulnerable period leading to death (Tilden, Thompson, Gajewski, \& Bott, 2012). Proposals for reducing turnover are multipronged, and include standard setting for staff hours per resident day, staff compensation, focused training in leadership and in geriatrics for RN staff, and upfront investments such as residency training for new hires and rewards and bonus programs. (Tilden, Thompson, Gajewski, \& Bott, 2012) .

\section{OVERVIEW OF LONG TERM CARE}

Long-term care focuses on patients who stay on an average of more than 30 days. During the patient's stay there are various health professionals that work collaboratively to provide care for the patient. Turnover may negatively impact how successfully the roles are able to function. In long-term care facilities, the following skilled professionals provide tiered levels of care. In most of the professions that operate within the long-term care environment, the tiers are well understood to those within the profession. This overview provides general information regarding the primary health care professionals, not all inclusive, that function within the long term care setting. One of the largest is that of Nursing. Nursing areas may include CNA's (Certified Nurse Aide/Nurse Assistants), RN's (Registered Nurses) and LPN's (Licensed 
Practical Nurses). The nursing director is a role that is operational and would require either an advanced degree or advanced skills within the field of nursing.

\section{CNAs}

CNAs are often called the eyes and ears of the environments in which they work because they see the patients often. Educationally, the standard typically required that a CNA be certified in the state in which they work and their names need to appear on the State Nurse Aid Registry. According to the Nursing Assistant Guide, there tends to be a high rate of turnover for CNA positions, which makes it easy to find work. The demand for CNAs is high, especially among establishments that supply continuing treatment and assisted living to elderly patients. A CNA will have many tasks and duties because the work will be with patients that have various levels of health.

Some of the tasks outside of the routine duties of a CNA in a long-term care facility include helping to record patient vital signs and other details and making contact with a nurse or doctor there is a decline in a patient's health or if they are developing a new illness, complication or injury. CNAs may also have the responsibility of some residents that will require assistance to completely bathe, dress, groom and/or feed them so that they can eat safely. These Nursing assistants play an important role in helping patients to avoid the development of bedsores, which is a very big part of maintaining quality care that is expected for all patients. If patients can be mobile on their own, you can help them to get up and moving so that they are not laying in one spot too long. You will help to rotate and move residents in their bed to prevent bedsores if they cannot move on their own. In some cases, the CNA might be helping to deliver medication to patients. This will depend on regulations in your state and the facility for which you work. You might also help to change dressings for patients who need wound care and perform some other basic first aid care.

\section{NURSES: RNS/LPNs}

Registered Nurses (RNs) are the largest segment of health professionals, and 48\% of them work in general medicine hospital. Most of the others work in doctor's offices, specialized hospitals, nursing homes and home health agencies (5-8\%). According to the American Nurses Association, Nurses must all be licensed through their state in order to practice as a nurse. However, there is more than 1 path to have the eligibility to license. Nurses may pursue an Associate degree in nursing (ADN) which is a 2 year degree or a Bachelor of Science in Nursing (BS/BSN) which is a 4 year. Graduate level education enhances the expertise of a licensed nurse with option to complete a Master of Science in Nursing (MSN) PhD (Doctor of Philosophy) and DNP (Doctor of Nursing Practice). Licensed practical nurses (LPNs) and Licensed vocational nurse (LVNs) positions usually require a year or so of specialized training after high school. The number of jobs for RNs is expected to grow $26 \%$ between 2010 and 2020. (DuPre', 2016).

In most long-term care facilities, the nurse collaborates with physicians, social workers, dieticians, speech language pathologists, physical therapists, occupational therapists, case managers, pharmacists, respiratory therapists, and other members of the interdisciplinary team. The interdisciplinary team is necessary in long-term care due to the elaborate complexity and extent of patient issues that now manifest in this setting. Long-term care nurses care for patients across the life span with numerous afflictions and diagnoses, although the majority of the patients are elderly. Patients with chronic disease processes such as hypertension, coronary artery disease, hypothyroidism, diabetes mellitus, chronic kidney disease, osteoarthritis, and chronic obstructive pulmonary disease receive care from long-term care nurses. Patients who have been afflicted with progressive illnesses such as Alzheimer's 
disease, multiple sclerosis, Parkinson's disease, and AIDS wasting complex are also cared for by long-term care nursing staff.

\section{Pharmacists}

Pharmacists provide a variety of services within the LTC setting. Pharmacy is another broad are and depending on the type of pharmacy it is will determine how the patients are services. The pharmacy has tiered roles as well, meaning that they pharmacy technicians and pharmacists have varying levels of professional responsibilities.

The Pharmacy Technicians are usually required to Pharmacy Technicians are not required by law to receive additional education beyond high school. However, the standard does require that you register with the state's board to work as a pharmacy technician. These requirements vary by state and select state require technicians to be nationally certified. Typically, the pharmacy technician's role requires a great deal of flexibility. Even if the state doesn't require pharmacy technicians to be certified, some employers by require it. The Pharmacy Technician Certification Board, for example, awards the Certified Pharmacy Technician (CPhT) credential to qualified candidates who pass a national certification exam (www.ptcb.org). CPhTs must recertify every two years by earning 20 continuing education credits.

The role of a long term care pharmacist is broad and varied. In long term care environments, the pharmacist's role is described as a dispensing pharmacist or consultant pharmacist. Dispensing Pharmacist provide services that are less clinical and typically operate in-house. Dispensing pharmacists. In the dispensing role, the pharmacists is expected to prepare medications by reviewing and interpreting physician orders, detect therapeutic incompatibilities and possible interactions between drugs, dispense medications by compounding, packaging, and labeling pharmaceuticals, control medications by monitoring drug therapies and advising interventions, completes pharmacy operational requirements, such as: organizing and directing technicians' work flow, verifying technician preparation and labeling of pharmaceuticals, verifying order entries, charges, and inspections, answer questions and requests made by health care professionals. Consultant Pharmacists are integrated into the clinical team and work alongside of the prescribing physician. The Consultant Pharmacist may have responsibilities that take them outside of the actual facility as they may travel within a geographic are in order to service patients and work alongside of the clinical team.

Educationally, the standard for becoming a pharmacist has now changed to a PharmD (Doctor of Pharmacy) degree. There may still be limited numbers of pharmacists who have the BSPharm degree in pharmacy. However, to secure a license to practice pharmacy, the NAPLEX exam, MPJE and in some states compounding medications is required. Pharmacists can attain additional Board Certifications in Specialty areas, which includes Geriatric Pharmacy (https://www.bpsweb.org/bps-specialties/)

\section{Hospice}

Hospice is a service that can be provided to patients who have been identified to have less than 6 months remaining to live. Hospice includes services of palliative care for physical, psychological, social and spiritual needs. The services can be provided in an inpatient setting or at home. To be paid, hospice must ensure that appropriate revenue codes are indicated for the LTC facility and that any discharge coding is correct for hospice services. 


\section{Home Health}

Home health is provided to patients who are confined to the home when services are ordered by a physician. Home Health services are provided by CNA's, LPNs and RN's and the number of hours can be determined by the time spent with each patient. Skilled services can be provided at a patient's home or in an LTAC or at the patient's home. It is based on the level of care that the patient needs. Acute, skilled or long term.

\section{CASE DESCRIPTION}

The long term care organization in this case was founded with a single skilled nursing facility and a servicing pharmacy. The founder recognized the advantages of combining a nursing home with a pharmacy since most long term care patients were typically prescribed multiple prescription medications. The organization remains a privately-owned organization which has applied the same economic advantages of vertical integration as it grew. With the addition of additional skilled nursing facilities, long term care organization types expanded to include a rehabilitation company, medical supplies, home health care, and hospice. Case management services were added to coordinate patient care with payment providers. Naturally, additional growth occurred in the pharmacy organization to accommodate geographic spread and state regulations.

With growth in the vertical integration of the organization, corporate support was added. Ultimately, this support required over 200 employees. Innovative leadership of the organization orchestrated a strategic plan that focused on growth through acquisition, modernization of facilities and equipment, and debt liquidation over a planning period of more than ten years. The organization developed a marketing strategic plan and implemented an administrator-in-training program to fill a growing number of long term care administrative positions.

Other innovations included the selection and purchase of an enterprise resource planning system to include financial and human resource systems. This initiative required more than two years to implement and included an impressive expansion of the information technology department. A centralization effort in this long term care organization involved streamlining the administrative functions of the operating units and the enlargement of these functions at the corporate level. Such things as billing, accounts receivable, accounts payable, and human resource management received attention during the centralization process.

Marketing was an emphasis following the ERP and centralization implementations. This involved a re-branding of the organization and the vertically integrated organizational elements. The management interest in marketing received a great deal of attention during which census was emphasized. Case mix was strategically emphasized, with Medicare paid rehabilitation emphasized during budgeting and admissions marketing. With pay-forperformance, these elements received priority value. Financial objectives were emphasized with marketing, case mix, census, billing, and accounts payable management receiving a lot of weight.

The result of these organizational priorities over several years had an unintended effect on human resource management. By placing attention on so many areas, and by including them in a pay-for-performance plan, little time and energy was left for the operating unit leaders to focus on the human resource needs of the operating units. By default, the inability to attend to many human resource basics ultimately led to degrading employee satisfaction and increased turnover. 


\section{ANALYSIS}

Turnover is calculated by determining the average number of active employees over a twelvemonth period and using that to divide into the total terminations for the same period and is presented as a percentage. In this case, turnover was totaled for each type of long term care organization (Table 1.) In this vertically integrated provider organization, turnover ranged from a low of $13.5 \%$ for the rehab company to a high of $84.6 \%$ for the skilled nursing company. Overall turnover was $74.5 \%$.

Table 1 - Long Term Care Turnover by Company Type

\begin{tabular}{|l|l|l|l|}
\hline Company Type & Avg Ct & Terms & T0 Rate \\
\hline Skilled Nursing & 6197 & 5243 & $84.6 \%$ \\
\hline Home Care & 153 & 77 & $50.5 \%$ \\
\hline Medical Supply & 34 & 17 & $50.0 \%$ \\
\hline Hospice & 403 & 195 & $48.4 \%$ \\
\hline Case Mgt. & 55 & 21 & $38.2 \%$ \\
\hline Corporate & 223 & 85 & $38.2 \%$ \\
\hline Pharmacy & 204 & 61 & $30.0 \%$ \\
\hline Rehab & 460 & 62 & $13.5 \%$ \\
\hline Overall & 7753 & 5774 & $74.5 \%$ \\
\hline
\end{tabular}

When considering turnover by the major positions in this long term care organization, the results ranged from a low of $4.1 \%$ for pharmacist to a high of $103.6 \%$ for certified nursing assistant (Table 2.) One factor in this case is that some position titles are used in different long term care company types. For example, LPN is a position in home care, hospice, skilled nursing, and case management. This overlap is considered, but the density of such positions with overlap is obviously greater in certain company types. Therefore, the total turnover for some positions may be dominant in one company, while some turnover occurred in other companies. A major position like this was that of administrative which occurred in each company type.

Table 2 - Long Term Care Turnover by Major Positions

\begin{tabular}{|l|l|l|l|}
\hline Position Type & Avg Ct & Terms & TO Rate \\
\hline CNA & 2653 & 2748 & $103.6 \%$ \\
\hline Dietary & 671 & 593 & $88.4 \%$ \\
\hline Delivery Driver & 13 & 10 & $76.9 \%$ \\
\hline Housekeeping & 559 & 409 & $73.2 \%$ \\
\hline RN & 491 & 354 & $72.2 \%$ \\
\hline LPN & 1197 & 828 & $69.2 \%$ \\
\hline Director of Nursing & 67 & 37 & $55.2 \%$ \\
\hline Religious Chaplain & 24 & 12 & $51.1 \%$ \\
\hline Laundry & 218 & 100 & $45.9 \%$ \\
\hline Maintenance & 115 & 53 & $46.1 \%$ \\
\hline Social Services & 128 & 58 & $45.0 \%$ \\
\hline Pharmacy Tech & 116 & 50 & $43.3 \%$ \\
\hline Administrative & 390 & 159 & $40.8 \%$ \\
\hline Recreation Activity & 126 & 45 & $35.7 \%$ \\
\hline Pharmacy Consultant & 22 & 7 & $31.8 \%$ \\
\hline Medical Records & 68 & 12 & $17.0 \%$ \\
\hline Speech Therapist & 76 & 12 & $15.8 \%$ \\
\hline Physical Therapist & 215 & 29 & $13.5 \%$ \\
\hline Occupational Therapist & 168 & 18 & $10.7 \%$ \\
\hline Pharmacist & 49 & 2 & $4.1 \%$ \\
\hline & & & \\
\hline
\end{tabular}




\section{CONCLUSION}

In this case, a rapidly growing, vertically integrated, long term care provider, operating in multiple states, was analyzed regarding the turnover rates of its operating companies across a calendar year. The results reveal a dramatic turnover issue which would challenge human resource management in any industry. Some facts were noticed. The higher the acuity, the higher the turnover. However, the larger the proportion of entry level positions, the higher the turnover. All clinical nursing related positions were excessively high. Pharmacists and therapists experienced the lowest turnover rates.

Considering pay levels, the turnover appears to be related to pay. The higher the pay, the lower the turnover, indicating this is an area for further research. In the field of human resource management in health care, turnover has long been felt to be directly related to the supervisory style of those who supervise entry level personnel. This paradox is compelling. Is turnover in long term care a matter of supervision, or is it a matter of pay? While this case analysis did not answer that question, it did provide a unique insight into the turnover issues of a vertically integrated long term care organization.

\section{References}

Black, P. (2015). Developing an Enhanced Perspective of Turnover and Retention of Nurses and Health Care Aides in Long term care Homes. Perspectives the Journal of Gerontological Nursing Association, pp. 25-30

DuPre', A. (2016) Communicating about health: current issues and perspective., $4^{\text {th }}$ ed., 114

Fitzpatrick, P. (2002). Turnover of Certified Nursing Assistants: A Major Problem for Long term care Facilities. Hospital Topics, 80(2), p. 21

http://allnurses.com/geriatric-nurses-ltc/long-term-care-746461.html. Accessed November 11, 2017.

http://CNA tips.com. Accessed November 13, 2017.

http://cnatraininghelp.com/cna-job-description/duties-long-term-care-facility/). Accessed November 9, 2017 http://doi.org/10.1097/MLR.0b013e3181a3cc62. Accessed November 13, 2017

https://learn.org/articles/What_are_the_Education_Requirements_for_Becoming_a_PharmacyTechnician.html. Accessed November 9, 2017

https://nursingassistantguides.com/what-is-a-certified-nursing-assistant-cna. Accessed November, 13, 2017

http://nursingworld.org/American Nurses Association. Accessed November 12, 2017

http://www.clintmaun.com/index.php5?cID=265. Accessed November 11, 2017

http://www.pharmacytimes.com/publications/career/2007/careers_2007-09/careers_2007-09_5081. Bodine. 2007. Accessed November 13, 2017

https://www.thebalance.com/working-in-a-long-term-care-pharmacy-what-it-s-like-2663849. Typical Long Term Care Pharmacists Job Description. Accessed November 12, 2017

Manthers, M. (2016). Population Reference Bureau. Retrieved from Fact Sheet: Aging in the United States: http://www.prb.org/Publications/Media-Guides/2016/aging-unitedstates-fact-sheet.aspx

McGilton, K., Boscart, V., Brown, M., \& Bowers, B. (2014). Making tradeoffs between the reasons to leave and reasons to stay employed in long term care homes: Perspectives of licensed nursing staff. Internationanl Journal of Nursing Studies, pp. 917-926. doi:doi:10.1016/j.ijnurstu.2013.10.015

Mukamel, D., Spector, W., Limcangco, R., Wang, Y., Feng, Z., \& Mor, V. (2009). The costs of turnover in nursing homes. Medical Care, 47 (10), 1039-1045

Tilden, V., Thompson, S., Gajewski, B., \& Bott, M. (2012). End-of-Life Care in Nursing Homes: The High Cost of Staff Turnover. Nursing Economics, 30 (3), 163-166 